
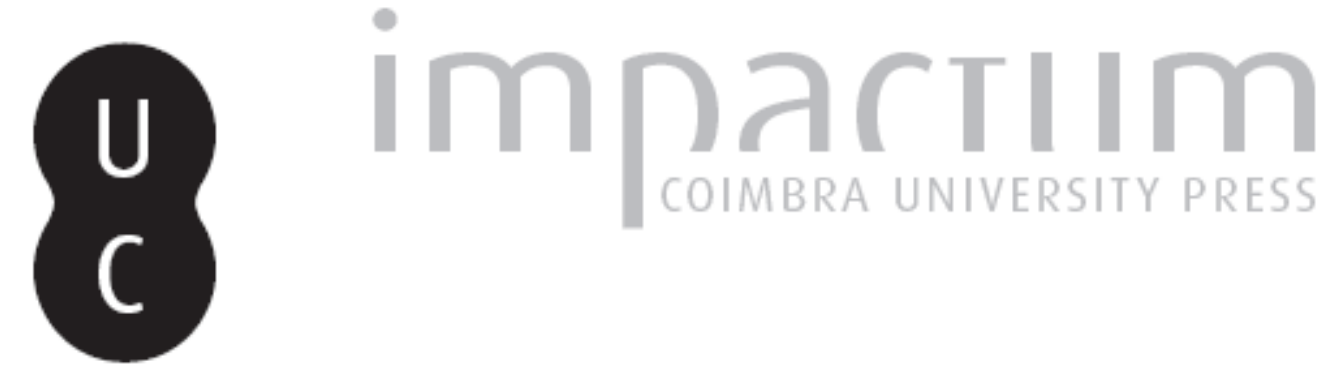

\title{
Riscos ambientais no Litoral: estudo comparativo Brasil-Portugal
}

Autor(es): $\quad$ Medeiros, Wendson; Cunha, Lúcio; Almeida, António Campar de

Publicado por: Faculdade de Letras da Universidade de Coimbra, Departamento de Geografia

URL

persistente:

URI:http://hdl.handle.net/10316.2/30208

DOI:

DOI:http://dx.doi.org/10.14195/0871-1623_31_10

Accessed : $\quad$ 26-Apr-2023 07:07:24

A navegação consulta e descarregamento dos títulos inseridos nas Bibliotecas Digitais UC Digitalis, UC Pombalina e UC Impactum, pressupõem a aceitação plena e sem reservas dos Termos e Condições de Uso destas Bibliotecas Digitais, disponíveis em https://digitalis.uc.pt/pt-pt/termos.

Conforme exposto nos referidos Termos e Condições de Uso, o descarregamento de títulos de acesso restrito requer uma licença válida de autorização devendo o utilizador aceder ao(s) documento(s) a partir de um endereço de IP da instituição detentora da supramencionada licença.

Ao utilizador é apenas permitido o descarregamento para uso pessoal, pelo que o emprego do(s) título(s) descarregado(s) para outro fim, designadamente comercial, carece de autorização do respetivo autor ou editor da obra.

Na medida em que todas as obras da UC Digitalis se encontram protegidas pelo Código do Direito de Autor e Direitos Conexos e demais legislação aplicável, toda a cópia, parcial ou total, deste documento, nos casos em que é legalmente admitida, deverá conter ou fazer-se acompanhar por este aviso.

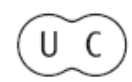




\title{
Riscos ambientais no Litoral: estudo comparativo Brasil-Portugal
}

\author{
Wendson Medeiros \\ Universidade do Estado do Rio Grande do Norte, Universidade de Coimbra/CEGOT \\ wendsonmedeiros@uern.br \\ Lúcio Cunha \\ Departamento de Geografia e Centro de Estudos de Geografia e Ordenamento do Território (CEGOT). Faculdade de Letras da Universidade de Coimbra. \\ luciogeo@ci.uc.pt
}

\section{António Campar de Almeida}

Departamento de Geografia e Centro de Estudos de Geografia e Ordenamento do Território (CEGOT). Faculdade de Letras da Universidade de Coimbra. campar@ci.uc.pt

\section{Resumo:}

O presente trabalho trata os riscos ambientais no Litoral dos territórios da Figueira da Foz (Centro de Portugal) e Areia Branca (Nordeste do Brasil), tendo como principal objetivo identificar e avaliar os riscos ambientais a partir de uma abordagem comparativa, fundamentada em trabalho de campo, interpretação de fotografias aéreas e imagens de satélite, bem como em contactos com as populações das áreas de estudo. Os riscos identificados apresentam magnitudes e expressões diferentes nos dois territórios, apontando para uma necessidade premente de monitorização e de implantação de ações de mitigação do risco, especialmente, no que tange ao planeamento e ordenamento do território.

Palavras-chave: Figueira da Foz. Areia Branca. Dinâmica costeira. Paisagem. Turismo.

\section{Résumé:}

Risques environnementaux dans le Littoral: une étude comparative Brésil-Portugal

Ce travail étudie les risques environnementaux dans le littoral des territoires de Figueira da Foz (Portugal central) et Areia Branca (Nord-est du Brésil) avec l'objectif principal d'identifier et d'évaluer les risques environnementaux à partir d'une approche comparative, basée sur des recherches de terrain, l'interprétation d'images de satellite et le contact avec la population. Les risques identifiés ont des amplitudes et des expressions différentes dans les deux territoires, en pointant sur un besoin urgent pour le suivi et la mise en œuvre des mesures d'atténuation du risque, en particulier dans la planification et le (ré)aménagement du territoire.

Mots-clés: Figueira da Foz. Areia Branca. Dynamique côtière. Paysage. Tourisme.

\section{Abstract:}

Environmental risks in the Coast: comparative study Brazil-Portugal

The present study relates the environmental risks in the Coast trough a comparative boarding between towns of the Figueira da Foz (Center of Portugal) and Areia Branca (Northeastern Brazil). The aim was the identification and assessment of environmental risks in an appliance context of territorial planning and management. The methods of study were based on empirical observations in land, contacts with the populations of study areas about the environmental risks and interpretation of satellite images. Most of the identified risks are present in both territories; however their magnitudes and expressions are different. According to the study, it is evident that Areia Branca city shows a better scenario in relation to the environmental risks, probably due to a low occupation throughout the Coast. Nevertheless, as the local tourism is growing, the local coast environment needs must be considered by the occupation planning because it points out some instability. Thus, it is still possible to minimize the future problems reducing the vulnerabilities due to the existing risks. The coast dynamics of Figueira da Foz acts as an important environmental risk specially the South of Mondego's estuary, because its consolidated occupation has been threatened by the coastal retreat, demanding urgent solutions to mitigate local risks and vulnerabilities; the mobility of the population, for example, may be seen as a solution which obliges to a different territorial organization.

Keywords: Figueira da Foz, Areia Branca. Coastal dynamics. Landscape. Tourism. 


\section{Introdução}

O estudo dos riscos constitui hoje um importante ramo das ciências, especialmente da Geografia, em que os riscos são abordados de diferentes maneiras, visando, quase sempre, o conhecimento das dinâmicas naturais e ambientais com intuito de aplicação ao planeamento e ordenamento territorial. É nesse contexto que o presente trabalho se fundamenta.

Integrado numa investigação mais ampla, ao nível de doutoramento em Geografia Física na Universidade de Coimbra, visa a identificação e avaliação de riscos ambientais no litoral, a partir de uma abordagem comparativa entre os territórios da Figueira da Foz (Centro de Portugal) e Areia Branca (Nordeste do Brasil; Figura 1). Tem como objetivo principal identificar e avaliar riscos ambientais e suas consequências a partir de trabalho de campo, interpretação de fotografias aéreas e imagens de satélite, bem como de contactos com as populações da área de estudo acerca do seu conhecimento dos riscos ambientais.

Várias situações justificam esta abordagem comparativa, no entanto, a importância dos riscos nos processos de ordenamento territorial reveste-se como o pano de fundo principal do trabalho. Inicialmente, devido ao facto de o território da Figueira da Foz, com ocupação antiga e consolidada, sofrer impactos relacionados com os riscos ambientais, o que exige a adoção de medidas de controlo e mitigação dos processos peri- gosos. Por outro lado, o município de Areia Branca, com um processo de ocupação recente e com perspetivas de intensificação da atividade turística, ainda não sofre com as manifestações de risco, mas apresenta uma dinâmica natural instável, exigindo estudos prévios que possam subsidiar as orientações para ocupação adequada do território, reduzindo, de forma preventiva, os riscos e as vulnerabilidades a eles associadas.

A conceção de risco aqui utilizada é uma conceção generalista e refere-se à probabilidade de ocorrência de um conjunto de processos ambientais perigosos, quer através da sua dimensão espacio-temporal, a perigosidade, quer através dos seus reflexos na sociedade, a vulnerabilidade.

Para fins de comparação, consideraram-se algumas características em comum dos dois territórios, especialmente, no que respeita ao uso e ocupação do solo. Embora haja uma clara distância temporo-espacial e tecnológica nos processos promovidos nos dois territórios, os tipos de usos dados aos mesmos assemelhamse bastante. Primeiro, o facto de abrigarem estuários onde se desenvolvem, ou se desenvolveram, atividades portuárias, piscatórias, salineiras, urbanas, agrícolas e de aquacultura. Em segundo lugar, pelo facto de terem no turismo uma atividade considerada importante no processo de desenvolvimento económico e territorial. Neste caso, há que destacar que enquanto a Figueira da Foz tem esta atividade perfeitamente consolidada, em Areia Branca o turismo está em processo de implemen-

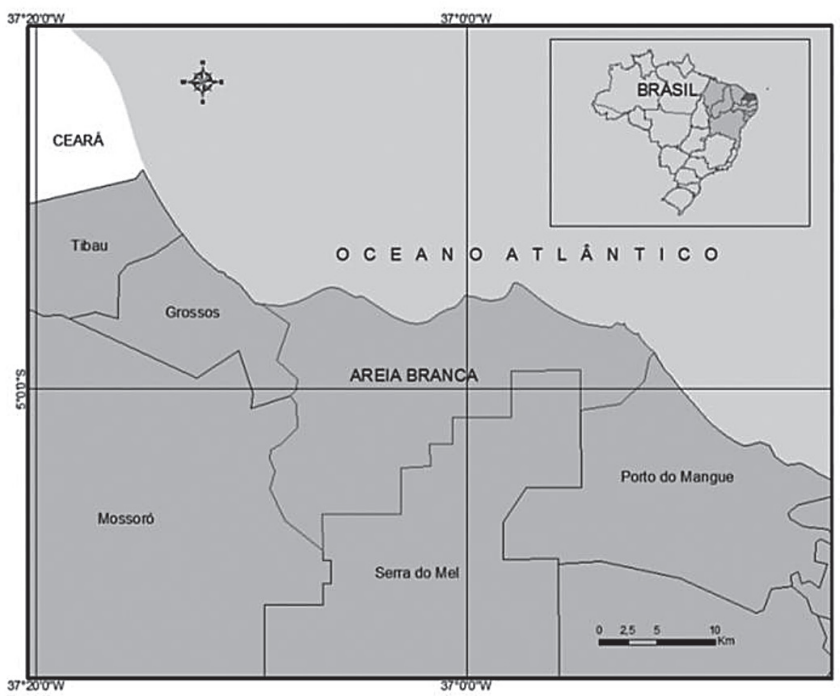

Figura 1

Localização das áreas de estudo.

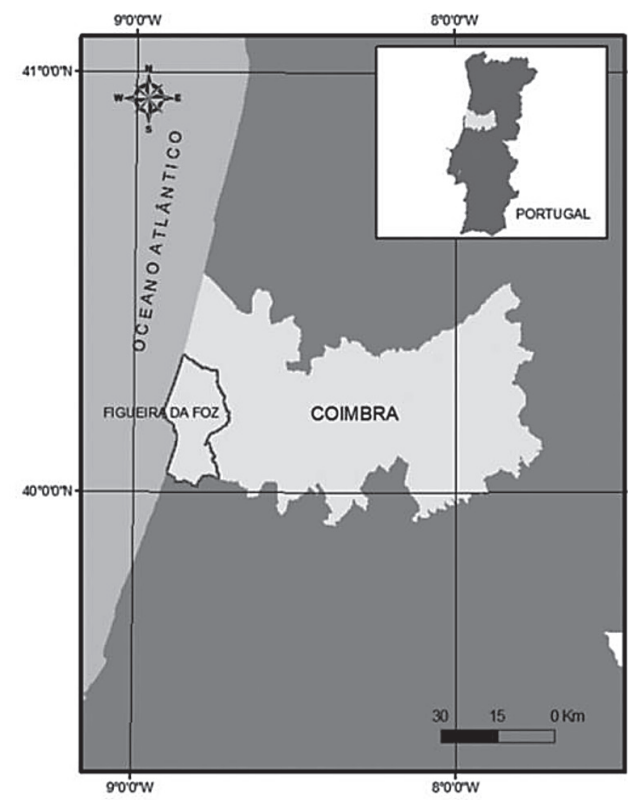


tação. Em ambas, a linha de costa, com suas paisagens exuberantes, é considerada o principal atrativo turístico. E, por último, os dois municípios desenvolveram ou desenvolvem atividades extrativas minerais que resultaram em transformações vincadas na paisagem, quer se trate das antigas pedreiras e minas de carvão na Figueira da Foz, quer se trate da intensa exploração petrolífera em Areia Branca. Porém, todas estas atividades assumem particularidades quanto à dimensão e importância para cada território, bem como quanto ao grau de interferência nas dinâmicas ambientais locais. Para se poderem comparar os efeitos destas atividades nos respetivos territórios, especialmente no que concerne aos processos de gestão do risco, começamos por caraterizar as dinâmicas ambientais de cada um deles e tentar fazer o inventário dos principais processos que poderão colocar em causa a sua qualidade ambiental.

\section{Breve caracterização do município de Areia Branca}

O município de Areia Branca está localizado na zona semiárida do Nordeste brasileiro, no litoral da Costa Branca do Estado do Rio Grande do Norte. Tem uma ocupação histórica iniciada no séc. XVII, vinculada ao município de Mossoró, mas que só assume um efetivo significado urbano no século XX. Apesar disso, as condições naturais favoráveis - ressalte-se a existência do estuário do rio Apodi-Mossoró, a vasta planície flúviomarinha e a escassez pluviométrica - favoreceram o surgimento de salinas artesanais com vista à produção de sal marinho. Esta atividade marca a paisagem do município desde o século XIX, tendo-se intensificado no século XX com o processo de mecanização nas salinas (FELIPE, 1986). Atualmente, esta atividade ocupa quase a totalidade da planície flúvio-marinha, correspondendo a uma área de $31 \mathrm{~km}^{2}$ (Medelros et al., 2011) do território do município, que possui área de 357,6 km² (IBGE, 2012).

A partir daí, Areia Branca, junto com Mossoró, Grossos, Macau e Galinhos passaram a assumir posição de destaque no cenário económico nacional, sendo hoje responsáveis por cerca de $90 \%$ de toda a produção de sal marinho do Brasil.

Mas, não são só as salinas que marcam a paisagem do município. A atividade petrolífera, impulsionada a partir de meados da década de 80 do século XX produziu mudanças significativas no interior do território municipal. Nos limites com o município de Mossoró, a Sul, está concentrado o maior campo produtor de petróleo em terra do Brasil, o do Canto do Amaro. Logo, na paisagem areia-branquense são comuns os cavalos mecânicos bombeadores do óleo, as estações coletoras e de tratamento do óleo bruto e as condutas no seio da caatinga, que servem tanto para escoar o óleo como para abastecer de água as unidades produtoras. De acordo com MEDEIRos et al. (2011), em 2006 esta atividade estava distribuída por uma área de $1,24 \mathrm{~km}^{2}$, dominada, principalmente, por tabuleiros costeiros.

Outro elemento que produziu alterações na paisagem foi a atividade de aquacultura, no caso para a criação de camarões. No entanto, estas alterações na paisagem não foram tão significativas, quer porque os tanques de água represada já eram comuns nas salinas, quer pela pequena área que ocupam, que corresponde a aproximadamente $0,79 \mathrm{~km}^{2}$ (Medeiros et al., 2011). Entretanto, esta atividade, por ter sido considerada de forte impacto ambiental, também foi selecionada neste processo de análise dos riscos ambientais.

Por fim, caracterizando a dinâmica territorial recente do município, duas outras atividades se mostram importantes: o turismo e a produção de energia eólica. A primeira apropria-se do cenário natural e construído do município, de forma conjugada: belas praias, falésias e dunas contrastando com os cavalos mecânicos do petróleo e as "dunas" de sal. Importante também para o turismo, do ponto de vista humano, é a dualidade existente a nível do ser humano, dividido entre a pesca e a pecuária, uma vez que o encontro do sertão com o mar torna este lugar singular no contexto do Nordeste do Brasil. Já a energia eólica, com o início de instalação de algumas usinas, promete causar um forte impacto visual na paisagem do município, desenvolvendo-se tanto no interior, onde predomina a mata de caatinga, quanto no litoral, nas dunas e arribas.

\section{Breve caracterização da Figueira da Foz}

Ao contrário de Areia Branca, o quadro natural da Figueira da Foz é marcado por um quadro climático mais favorável, um clima de base mediterrânica, muito menos seco e com a pluviosidade diferentemente distribuída pelas duas estações, verões quentes e secos e invernos tépidos e chuvosos.

A existência do mar e do estuário do maior rio completamente português propiciou uma ocupação voltada também para a pesca e para a produção do sal marinho, bem como dinamizou a atividade turística. Mas, a ocupação é, aqui, muito mais antiga do que em Areia Branca, remontando pelo menos ao século I e tendo-se intensificado a partir da reconquista aos mouros em 1064 e da reocupação em 1080 (BoRGEs, 1991). É, 
no entanto, a partir do século XVIII que a Figueira da Foz conheceu um grande crescimento demográfico e urbano, devido ao movimento do porto e ao desenvolvimento da indústria de construção naval. Com isso, as modificações na paisagem tornam-se mais severas, sendo difícil, muitas vezes, identificar elementos naturais, na aceção restrita do termo.

Trata-se, portanto, de uma cidade e de uma região muito dinâmica do ponto de vista dos serviços, especialmente do turismo, que a tornou conhecida como a Praia da Claridade e mais recentemente incluída na chamada Costa de Prata, numa alusão às cores de suas praias. Além disso, possui uma paisagem marcada também por relevo baixo aplanado, apenas ondulado pelas dunas revestidas de pinhal, e com a ilha da Morraceira, onde durante muitos séculos se produziu o sal marinho. A exceção orográfica está na serra da Boa Viagem $(258 \mathrm{~m})$ e no seu cabo Mondego, uma arriba ativa no extremo ocidental da serra. As dunas, do sector setentrional são marcadas também por algumas lagoas de origem interdunar, sendo numa delas, a maior, praticada a pesca pela população local.

\section{Materiais e métodos}

Os principais métodos utilizados nesta investigação foram as observações empíricas realizadas no terreno e os levantamentos bibliográficos. Foram feitas incursões em janeiro, maio e junho de 2011, e fevereiro de 2012 na Figueira da Foz; e em julho e dezembro de 2010, em Areia Branca. Durante o trabalho de campo foram feitas observações diversas acerca dos impactos, riscos e paisagem dos dois municípios, sendo para isso, fundamentais as observações empíricas sob a ótica da Geografia Física. Assim, foram identificadas situações de risco ambiental que foram, posteriormente, agrupadas em função da unidade de paisagem em que se inserem e da atividade por elas responsável. Além disso, efetuou-se interpretação visual das imagens do Google Earth, visualizando a série histórica disponível para os dois municípios, que vai de 2003 a 2010.

\section{Resultados e discussão}

Com vista a esboçar uma comparação preliminar fez-se uma avaliação generalizada de cinco tipos de riscos identificados e também relatados pelas populações das áreas de estudo. 0 quadro I apresenta os resultados dessa comparação, onde se avaliaram os riscos quanto à sua significância (ou grau de importância em relação aos efeitos dos fenómenos perigosos) e origem.

Quadro I

Principais riscos ambientais identificados e classificação genérica*

\begin{tabular}{|l|c|c|}
\hline \multicolumn{1}{|c|}{ Riscos Ambientais } & Areia Branca & Figueira da Foz \\
\hline Avanço do mar & $2 \mathrm{n}$ & $4 \mathrm{~m}$ \\
\hline Incêndios florestais & $1 \mathrm{t}$ & $4 \mathrm{~m}$ \\
\hline Desertificação & $2 \mathrm{~m}$ & $1 \mathrm{~m}$ \\
\hline Inundações & $3 \mathrm{~m}$ & $2 \mathrm{~m}$ \\
\hline Poluição ambiental & $3 \mathrm{t}$ & $3 \mathrm{t}$ \\
\hline Avanço de dunas & $3 \mathrm{n}$ & $2 \mathrm{~m}$ \\
\hline
\end{tabular}

* Significância (1- Não preocupante; 2 - Pouco preocupante; 3 - Preocupante; 4 - Muito preocupante). Origem ( $\mathrm{n}$ - natural; $\mathrm{t}$ - tecnológica; $\mathrm{m}$ - mista).

\section{Avanço do mar}

O avanço do mar, fenómeno de caráter global e muitas vezes associado às mudanças climáticas, manifesta-se de forma diferente nos dois municípios. É um tipo de risco muito presente na Figueira da Foz, sobretudo no sector meridional em função das sucessivas obras de engenharia pesada na barra do porto, sendo inclusivamente responsável por diversas medidas governamentais com o intuito da mitigação e gestão deste processo perigoso. Isto torna o município imbuído de uma cultura de risco no planeamento e ordenamento territorial, algo ainda inexistente no caso de Areia Branca. São comuns as obras de contenção ou minimização deste risco ao longo do litoral da Figueira da Foz. No entanto, apesar de minimizar as consequências desse processo, os efeitos danosos ainda são muito frequentes, especialmente, no inverno. Recentemente, passadiços, obras de contenção e estradas foram afetadas por este processo (Figura 2).

No município de Areia Branca esse processo ainda é pouco preocupante, o que decorre de vários aspetos, particularmente da baixa densidade de ocupação litoral. Assim, são fracos ou praticamente nulos os efeitos danosos desse processo. Outro aspeto que pode ser considerado é o facto de a deriva litoral ser predominantemente E-W e o município estar situado a Leste do estuário do rio Mossoró, portanto a barlamar da deriva. Nota-se, por exemplo, que a Oeste do estuário, o litoral de Grossos, no município vizinho, já sofre com efeitos erosivos associados à ação do mar (CARVALHO, 2011).

Outra comparação que pode ser feita e consta da avaliação sucinta aqui apresentada é a origem para esse fenómeno. Enquanto na Figueira da Foz se pode considerar uma origem mista, em que se combinam fatores naturais (elevação do nível dos oceanos, por exemplo) com fatores antrópicos (barragens nos principais rios; obras estruturantes portuárias no estuário do 


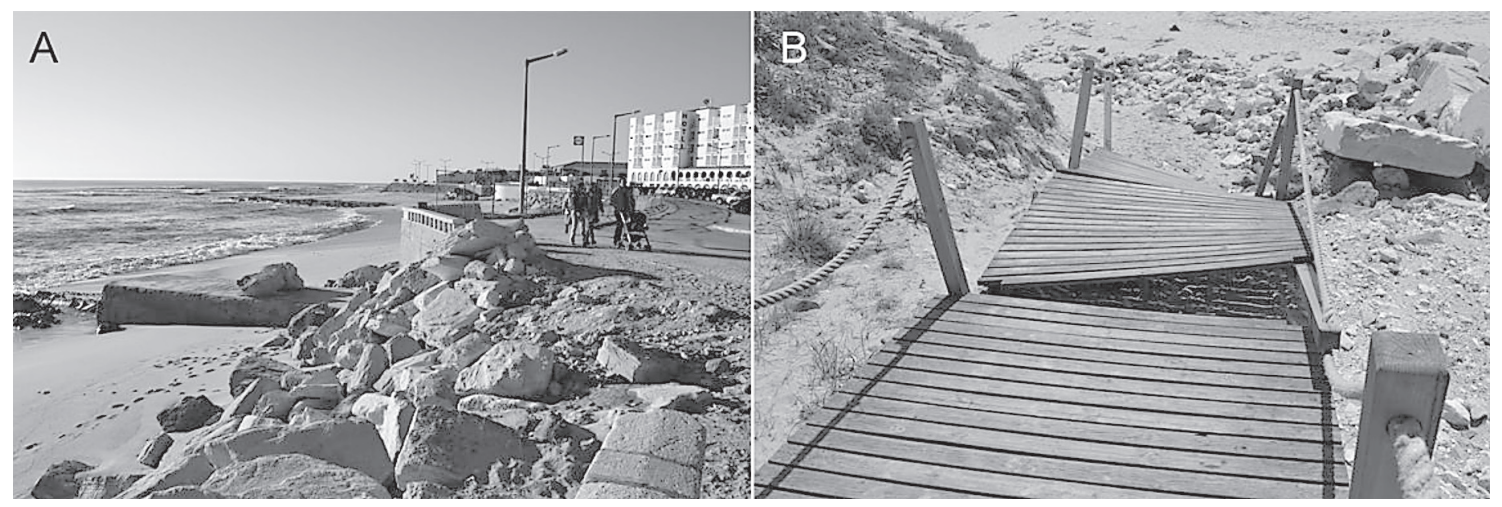

Figura 2

Aspetos da destruição causada pelo mar no calçadão de Buarcos (A - fev/2012) e no passadiço da praia da Leirosa (B - mai/2011)

Fotos: Wendson Medeiros

Mondego; avanço da urbanização em áreas costeiras, que interferiram na dinâmica oceânica e estuarina natural (Arrotela, 1985; Cunha et al., 1997; Dinis e Cunha, 1998; Ribeiro, 2006), em Areia Branca a origem é mais relacionada com fatores naturais, embora não se descarte a possível interferência humana na dinâmica sedimentar, visto que no ano 2002 foi construída uma grande barragem a montante de Areia Branca (Barragem de Santa Cruz, com capacidade de acumulação em torno de 600 milhões de $\mathrm{m}^{3}$ ), que pode já estar resultando na diminuição de sedimentos transportados pelo rio.

Apesar de o fenómeno ser ainda pouco preocupante em Areia Branca, pensamos que é suficientemente importante para que seja considerado no âmbito dos processos de planeamento e ordenamento do território, principalmente, por este município estar em processo de instalação de infraestruturas de suporte à atividade turística, podendo-se citar, como obras previstas, a construção de uma ponte sobre o estuário, bem como calçadões e estradas próximos da orla costeira para facilitar a instalação de equipamentos turísticos.

\section{Incêndios florestais}

Por serem bastante frequentes em Portugal continental, em razão da combinação de fatores naturais (clima de base mediterrânica, com verões secos e por vezes muito quentes; trovoadas com faíscas - Lourenço, 2004) e antrópicos (mau ordenamento florestal; biomassa combustível nas florestas, especialmente, pinheiros, eucaliptos e os matos do sub-bosque), são comuns os avisos sobre este tipo de risco nas matas da região da Figueira da Foz. Ressalte-se a homogeneidade de espécies florestais como os pinheiros ou eucaliptos na composição das matas, espécies que são altamente combustíveis e auxiliam na propagação dos fogos, fator acentuado quando ocorrem ventos fortes e estão plantados em vertentes. Além disso, a ação criminosa de ateadores de fogos, o desleixo ou incúria das pessoas e a ausência de uma manutenção e vigilância mais eficaz no que diz respeito à limpeza da floresta podem ser somadas aos fatores naturais condicionantes e desencadeantes deste processo perigoso.

Já em Areia Branca os incêndios florestais são quase inexistentes. E quando ocorrem, são claramente tecnológicos, vinculados seja a ações agrícolas (para limpeza e preparação dos terrenos), seja a acidentes com a indústria extrativa petrolífera. Neste último caso, apesar de não serem tão frequentes, podem assumir dimensões grandiosas devido ao clima semiárido nos períodos desfavoráveis, quando a mata de caatinga (predominante nas áreas de extração petrolífera) se apresenta seca e os solos com baixa ou quase nenhuma humidade. Embora não esteja também previsto no planeamento urbano, este risco já faz parte dos planos preventivos vinculados à atividade petrolífera (Figura 3).

\section{Desertificação}

O processo de desertificação é resultante da atuação de fatores naturais (climas áridos ou semiáridos severos) e humanos (má gestão dos recursos naturais resultando em degradação ambiental generalizada) que promovem, entre outras consequências, o empobrecimento dos solos e, com isso, a inviabilização de manutenção de vegetação. Em suma, a desertificação produz todo um impacto profundo na dinâmica dos ecossistemas, fazendo-os evoluir na direção de novos desertos.

Embora no caso da Figueira da Foz este processo não seja preocupante, principalmente, em razão das características climáticas regionais, em Areia Branca já tem que haver preocupação com este processo. Embora 

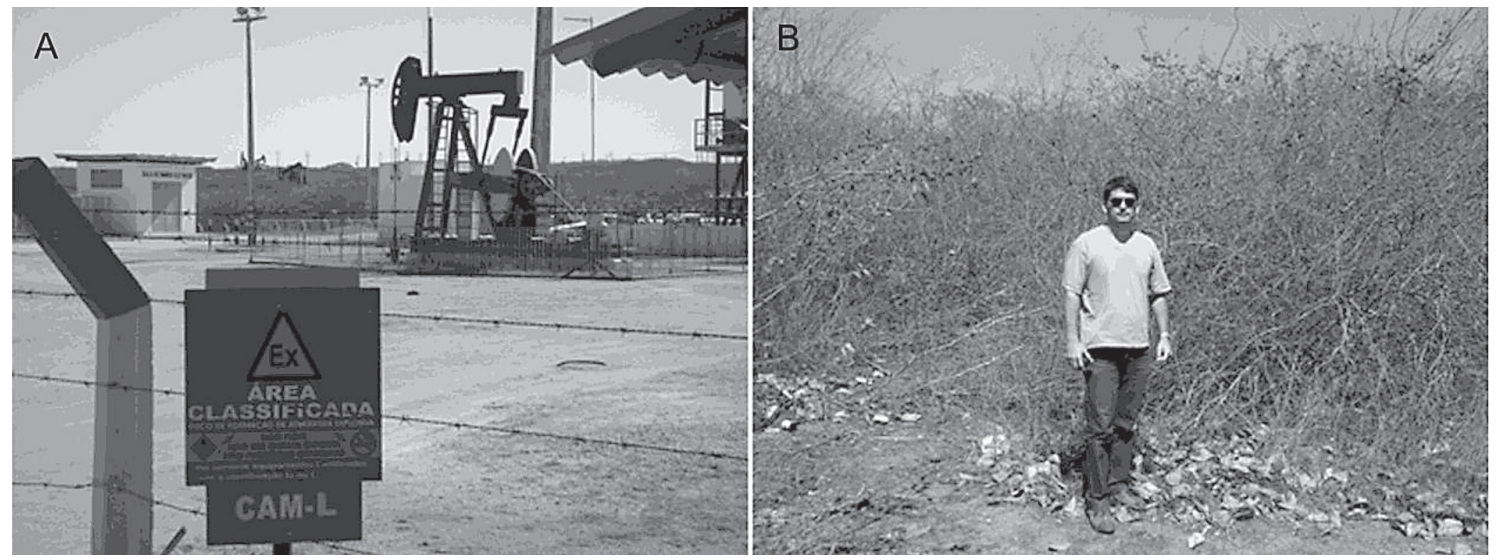

Figura 3

Aviso de risco de explosão em unidade produtora de petróleo (A) e aspetos da Caatinga seca (B) em Areia Branca

Fotos: Wendson Medeiros - ago/2010

fora da área delimitada como Núcleo de Desertificação do Seridó, o único no Rio Grande do Norte, a degradação ambiental que resulta da atividade petrolífera e, agora, da atividade de produção de energia eólica, pode contribuir para que essa situação se estenda ao município. 0 rigor de um clima semiárido associado ao desmatamento da caatinga e à existência de solos delgados ou pouco férteis são alguns dos elementos que podem gerar preocupação em termos de desenvolvimento desse processo.

\section{Inundações}

As inundações são aqui tratadas de modo geral e englobam as inundações pluviais, fluviais e marinhas, bem como as inundações rápidas urbanas.

Desse modo, ambas as áreas de estudo apresentam suscetibilidade natural a este risco, em função das suas características locacionais em áreas de planícies (cotas reduzidas), em baixos cursos de rios com intensa modificação. Na Figueira da Foz, as cheias e as consequentes inundações sempre foram muito frequentes, havendo muitos relatos de águas invadindo a cidade e inundando os campos do Mondego, trazendo prejuízos a atividades diversas (ArRotelA, 1985). Contudo, as obras de regularização do leito do Mondego, realizadas nos anos 70 e 80 do século passado, possibilitaram a redução de frequência desse risco, tornando-o, hoje, pouco preocupante. Sua origem é considerada mista, visto que é o resultado das ações combinadas do clima com as modificações feitas na drenagem natural, seja com a construção de canais, seja com a expansão urbana para áreas de várzea.

Em Areia Branca, este fenómeno também assume origem mista. As cotas reduzidas na planície são um fa- tor importante. Entretanto, a ocupação de quase toda a planície flúvio-marinha com a atividade salineira, que passou a confinar a cidade numa forma de ilha, intensifica o processo de inundações. Como não há para onde escoar as águas das cheias, parte da cidade mais baixa fica sempre inundada nos períodos chuvosos. Além da inundação tipicamente pluvial, o assoreamento na foz do rio Apodi-Mossoró contribui para que, no período chuvoso, suas águas inundem as cidades e, aí, há também a presença de água no largo da igreja matriz. Por isso, neste município, este é um risco preocupante e carece de medidas urgentes no que respeita a ações de defesa civil e de planeamento e ordenamento territorial.

\section{Poluição ambiental}

Entendida como a emissão para o ambiente de matérias, partículas ou energias que resultem em degradação, os dois municípios apresentam este risco como preocupante e com origem principalmente tecnológica, isto é, ligada às atividades produtivas e seus processos tecnológicos.

Apesar de preocupante, as diferenças entre as duas áreas são muitas. A Figueira da Foz apresenta um dinamismo muito maior, com uma diversidade e intensidade produtivas muito além do município de Areia Branca. Neste último, as condições mais próximas da natureza são mais frequentes e o desenvolvimento intenso da atividade petrolífera e das salinas, principalmente, produzem danos ambientais preocupantes, como a contaminação dos solos e dos recursos hídricos (superficiais e subterrâneos) por óleo ou pelas águas-mães (resíduos das salinas, em regra lançados diretamente na drenagem natural). Neste último caso, em 1998 o rio do Carmo, afluente do rio Apodi-Mossoró sofreu um dos maio- 


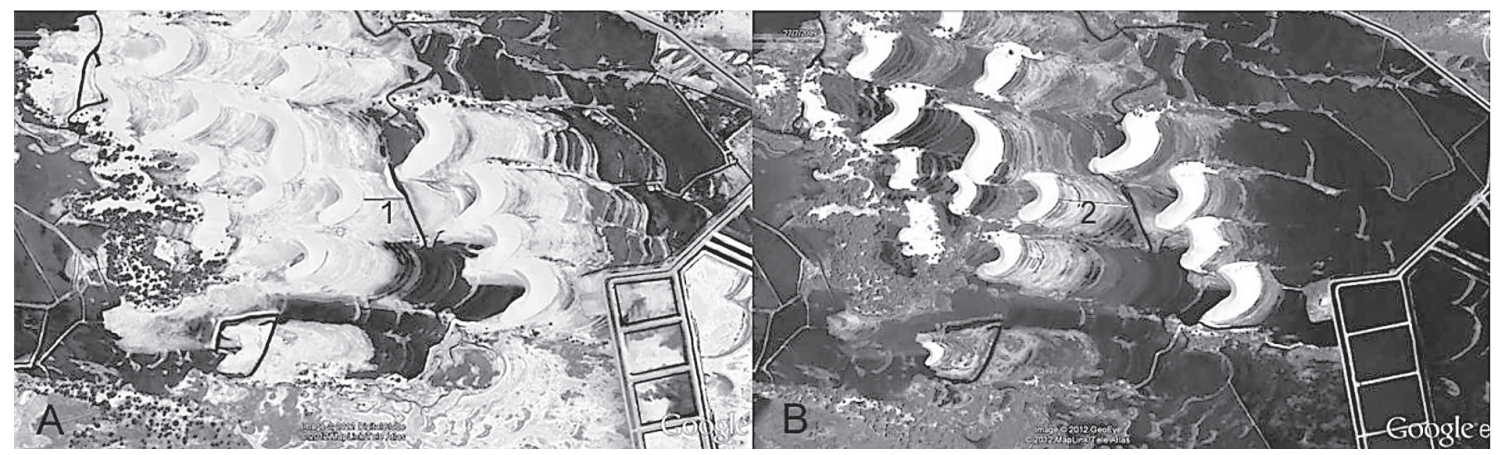

Figura 4

Dunas avançam 103 metros entre os anos de 2005 (A - ponto 1) e 2009 (B - ponto 2) em Areia Branca

Fonte: Google Earth

res acidentes ambientais do Rio Grande do Norte. 0 lançamento in natura das águas-mães provocou a salinização desse afluente, resultando na morte da quase totalidade de sua fauna bentónica (OLIVEIRA, 2001).

Na Figueira da Foz, além da poluição gerada pelas atividades diversas na área urbana e nos campos agrícolas na planície do Mondego, destaca-se a preocupação com a poluição na área da Leirosa, com a indústria de celulose. Aí, as comunidades locais já se sentem incomodadas com os fumos da atividade e, também, com os reflexos nas praias das descargas através dos emissários submarinos que lançam no mar, desde 1995, os efluentes desta atividade.

\section{Avanço de dunas}

O avanço de dunas é constante na região de Areia Branca. Primeiro, em função dos constantes ventos de direção predominante ESE, depois do vasto campo de dunas móveis encontrados nas localidades de Cristóvão,
Redonda e Ponta do Mel. Estas dunas, de idades recentes (em torno de 24700 a 9400 anos, segundo Barreto et al., 2004) migram com uma velocidade média de 25,75 $\mathrm{m} /$ ano (determinada através da leitura de imagens de satélite e de contactos com a população no campo; Figura 4), provocando danos ambientais diversos. 0 encerramento de estradas de acesso a estas localidades tem sido constante, especialmente, para Cristóvão. Em Redonda, o povoado já mudou de lugar por 3 vezes, estando ainda à mercê da evolução natural deste processo que, caso não ocorram intervenções, poderá vir a atingir parte da localidade novamente. Tendo em vista a baixa ocupação e a quase não interferência das atividades humanas nesse processo, considerou-se como um risco natural e muito preocupante.

$\mathrm{Na}$ Figueira da Foz, as dunas, em sua maioria, não representam um risco, pelo menos por comparação com a situação de Areia Branca. Isso decorre da sua estabilização proporcionada pela ocupação florestal,
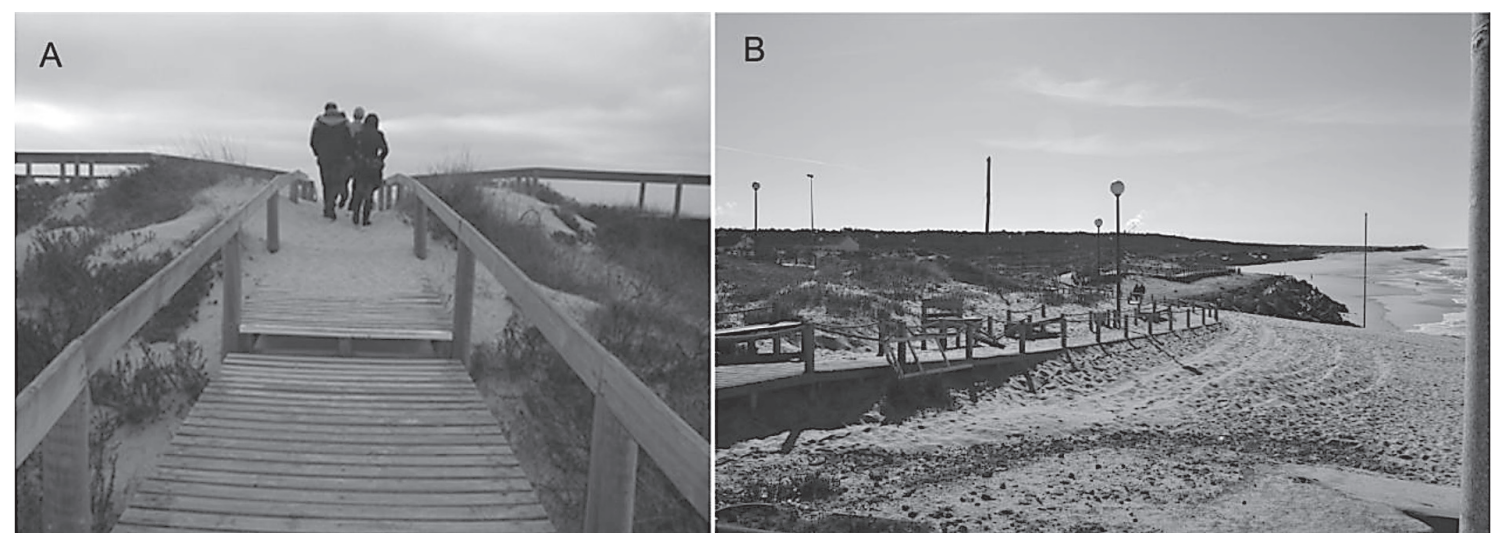

Figura 5

Areias avançam sobre passadiços nas praias de Quiaios (A - mai/2010) e Costa de Lavos (B - jan/2012)

Fotos: Wendson Medeiros 
especialmente, de pinheiros, plantados desde o séc. XIX, a sul do Mondego e desde a década de 20 do séc. $X X$, a norte, e que as fixou. No entanto, as ações de artificialização da costa, às vezes com a construção de dunas artificiais, somadas à dinâmica natural dos ventos e marinha, produziram dunas frontais (primárias) que além de funcionarem como proteção ao avanço do mar, tendem a migrar para as áreas urbanas ou, em alguns casos, a soterrar passadiços construídos para facilitar o acesso a algumas praias. Isto ocorre em praticamente todas as praias do Sul, mas também no Norte (Figura 5).

\section{Riscos e ordenamento do território}

Ao compararmos os riscos nos dois municípios e ao atribuirmos uma valoração dos mesmos, percebe-se, grosso modo, um pouco das realidades observadas, porém, não se consegue perceber de forma segura os impactos completos destes processos perigosos. Para isso, seria necessário contextualizar a avaliação às estratégias de planeamento e ordenamento do território nos dois países.

Areia Branca possui Plano Diretor, elaborado no ano 2005. No entanto, a ausência de uma cultura do risco na região justifica o não tratamento de alguns destes riscos. Caso contrário ao da Figueira da Foz, que tem suas estratégias de ordenamento fundamentadas nas premissas do risco (PROT, PDM, PMOT, POOC). Sendo assim, algumas das situações, embora pareçam pouco significativas do ponto de vista da valoração, assim o são em função da ausência ou dos processos de planeamento e ordenamento do território.

Como enfatizou Fernando Rebelo (2010), o estudo dos riscos deve estar presente em todos os processos de ordenamento territorial, no entanto, naqueles territórios em que ainda não há ocupação urbana, ou que estão à espera de ocupação, estes estudos devem ser considerados de modo prévio. É o que acontece em Areia Branca. Com um processo inicial de ocupação da costa pela atividade turística, faz-se mister que esses riscos sejam levados em conta, de forma a orientar, de modo seguro, a ocupação turística. Assim, espera-se evitar problemas futuros de contenção dos riscos que impliquem altos recursos financeiros e humanos e que, na maior parte das vezes, não resolvem por completo os problemas.

A Figueira da Foz, com uma ocupação consolidada, já é encarada de outra forma. Mas, pode servir de exemplo para o ordenamento de Areia Branca. Hoje, na Figueira da Foz investem-se recursos elevados com o in- tuito de proteger as costas e praias, com construção de esporões e ações da defesa civil. Em alguns casos as ações não têm tido um êxito total, transformando-se numa situação de alerta frequente e de investimentos ininterruptos para solucionar o problema. Uma das formas possíveis pode incluir a relocalização de povoações, produzindo custos elevados e transtornos de toda a ordem, inclusivamente de ordem cultural e psicológica.

É com o intuito de possibilitar, prever e agir antecipadamente que se propõe um ordenamento adequado em termos de ocupação turística da Areia Branca.

\section{Considerações finais}

Tendo em vista que se trata de um trabalho em curso, a única afirmação que se pode fazer neste momento é que existe uma necessidade clara de monitorizar estes processos com vista a propor um ordenamento territorial mais adequado para a minimização dos riscos e, consequentemente, das suas vulnerabilidades. No caso de Areia Branca é mais fácil atuar, uma vez que a ocupação, especialmente a turística, ainda não está consolidada e não ocupa de forma densa o território municipal. Na Figueira, o ordenamento territorial visando reduzir as vulnerabilidades deveria passar pela remoção ou relocação de algumas comunidades, especialmente da Leirosa e Costa de Lavos, em outras posições mais seguras ou investir em obras que possam garantir um maior controlo do mar, como paredões paralelos à costa, sob a forma de recifes artificiais, o que possibilitaria a dissipação da energia das ondas e seu poder erosivo, embora não solucionasse completamente o problema. Em Areia Branca há uma área com beach rocks o que impede, naturalmente, a força das ondas na costa, poupando-a à força da erosão.

\section{Referências Bibliográficas}

Arrotela, J. C. (1985) - Figueira da Foz: a cidade e o mar. CCRC, Coimbra.

Barreto, A. M. F.; Suguio, K.; Bezerra, F. H. R.; Tatumi, S. H.; Yee, M. e GiAnnini, P. C. F. (2004) - "Geologia e geomorfologia do Quaternário costeiro do Estado do Rio Grande do Norte”. Geologia USP, vol. 4, $\mathrm{n}^{\circ}$ 2, pp. 1-12.

Borges, J. P. A. (1991) - Figueira da Foz. Lisboa, Presença, Série Cidades e Vilas de Portugal, 12.

Carvalho, R. G. (2011) - Análise de Sistemas Ambientais aplicada ao planejamento: estudo em macro e mesoescala na região da bacia hidrográfica do rio Apodi-Mossoró, $R N /$ 
Brasil. Tese de doutoramento em Geografia, Universidade Federal do Ceará, Fortaleza-CE.

CUnHA, P. P.; PInTo, J. e DinIs, J. L. (1997) - "Evolução da fisiografia e ocupação antrópica na área estuarina do Rio Mondego e região envolvente (Portugal centro-oeste), desde 1947". Territorium, 4, pp. 99-124.

DinIs, J. L. e CunHA, P. P. (1998) - "Impactes antrópicos recentes no sistema sedimentar do Estuário do Mondego (Portugal central)". Sociedade e Território, 27, Setúbal, pp. 3-15.

FELIPE, J. L. (1986) - Elementos de Geografia do RN. Editora da UFRN, Natal-RN.

IBGE. Fundação Instituto Brasileiro de Geografia e Estatística (2012) IBGE Cidades@Areia Branca. [suporte digital]. Disponível em: www.ibge.gov.br/cidadesat/topwindow.htm?1. [Acesso em 20 mar. 2012].

LOURENço, L. (2004) - Manifestações do risco dendrocaustológico. Coimbra, NICIF, FLUC, Col. Estudos, 50.
Medeiros, W.; Cunha, L. e Almeida, A. C. (2011) - "Dinâmica territorial e impactos ambientais no município de Areia Branca-RN (Nordeste do Brasil): uma análise preliminar". Revista Geográfica de América Central, número especial EGAL, Costa Rica, pp. 1-14.

Oliveira, J. P. (2001) - Dinâmica sócio-espacial e degradação ambiental da sub-bacia do Rio do Carmo, Mossoró-RN. Dissertação de Mestrado em Desenvolvimento e Meio Ambiente, Universidade do Estado do Rio Grande do Norte, Mossoró-RN.

Rebelo, F. (2010) - Geografia Física e Riscos Naturais. Imprensa da Universidade de Coimbra, Coimbra.

Ribeiro, J. L. (2006) - Centralidade geo-ambiental do estuário do Mondego no ordenamento da zona costeira da Figueira da Foz. Tese de doutoramento, Faculdade de Letras da Universidade de Coimbra, Coimbra. 